\title{
Acquired but not Required ? : \\ the Gap between the Competency in Education and That in Action for School Librarianship
}

\author{
Takuma NAKAMURA \\ Graduate School, Aoyama Gakuin University \\ 4-4-25 Shibuya, Shibuya-ku, Tokyo \\ Japan \\ d9114001@aoyama.jp \\ Fumie NIWAI \\ Keio Futsubu Junior High School \\ 1-45-1 Hiyoshi-honcho, Kohoku-ku, Yokohama-shi, Kanagawa \\ Japan \\ fniwai@z8.keio.jp \\ Mitsuhiro ODA \\ Aoyama Gakuin University \\ 4-4-25 Shibuya, Shibuya-ku, Tokyo \\ Japan \\ m-oda@ephs.aoyama.ac.jp \\ Teruyo HORIKAWA \\ Aoyama Gakuin Women's Junior College \\ 4-4-25 Shibuya, Shibuya-ku, Tokyo \\ Japan \\ t61353@aoyamagakuin.jp \\ Yutaka MABE \\ Teikyo Heisei University \\ 4-21-2 Nakano, Nakano-ku, Tokyo \\ Japan \\ y.mabe@thu.ac.jp
}




\begin{abstract}
This study confirms the gap between the competency of "school librarian" in education and that in action. The authors carried out the semi-structured interviews with eight persons who had experience of working as a school librarian. The authors asked them whether they thought that it was necessary to learn the competency in the list made by authors, and whether they utilized that at their works. As a result, most of the competencies was required at work, moreover, it was necessary to learn in education. According to their answers, the authors recognized following things. Firstly, there was little need to learn some competencies in the categories of library management and organization of materials. Secondly, the competencies about history, other types of library and school librarianship of foreign countries should be learned in education, though those were not utilized at work. Thirdly, the competency of pedagogy should be added to the list.
\end{abstract}

Keywords: school librarianship, competency, LIS education

\title{
The gap between the competency in education and that in action
}

In Japan, there are two types of librarian in school library: "teacher librarian" and "school librarian". However, their roles and competencies are not clear. This study confirms whether competencies of teacher librarian and school librarian are the same as those that acquired in qualification program for teacher librarian and public librarian. There is no certification system of school librarian in Japan. Therefore, school librarians are sometimes required having a certification of public librarian. For that reason, the authors focused on the program for public librarian.

\section{Interview with teacher librarian and school librarians}

First of all, the authors have tried to make two lists: one included the competencies of teacher librarian, other did the competencies of school librarian. Then, the authors have carried out semi-structured interviews with eight persons who had experience of working as a teacher librarian. In addition, the authors have done eight people who had that as a school librarian. The authors have asked them three questions; (1) Do you think that there is need to learn each competency in this list?; (2) Do you utilize each competency at your work?; (3) Are there any abilities that should be learned in education except the competencies in this list? Authors have already reported the result of this study about the competencies of teacher librarian. Here, this poster focuses on the results about school librarians. 


\section{Is the competency required?}

As a result, the present study shows that most of the competencies in the list was required at their works, moreover, it was necessary to learn in course. However, there are some gaps between the competencies of school librarian in education at universities and those in action. According to their answers, the authors recognized following things. Firstly, the results show that there is little need to acquire the competencies in the categories of library management (e.g library management evaluation) and organization of library materials (e.g. Japanese Cataloging Rules). In particular, interviewees thought that the competencies about market testing, AACR and FRBR are not used and have not to learn. Secondly, the competencies about history, other types of library and school librarianship of foreign countries should be learned in education, though those had not been utilized at work. The reason is that these competencies are needed to understand the background of school library, however, those are not connected with daily works. Thirdly, according to answers to third question, the competency of pedagogy (e.g. collaboration with teachers, curriculums and school system) should be added to the list. The list is based on the qualification program for public librarian, therefore, it doesn't include these competencies.

Note: This study was supported by JSPS Grant-in-Aid for Scientific Research (KAKENHI) (C) Grant Number 26330368.

\section{Biographical note}

Takuma NAKAMURA is a research student at Department of Education, Graduate School of Education, Psychology and Human Studies, Aoyama Gakuin University, Japan. His main research topics are educational function of libraries, librarian's competencies for supporting learner, and library user education.

Fumie NIWAI has worked as a teacher librarian at a private junior high school in Yokoyama City in JAPAN for 15 years, and she is a student of doctor's program at Aoyama Gakuin University in Tokyo. Her main research topic is library use education and information literacy education for the junior high school students. These come from her actual practice at the school library.

Mitsuhiro ODA is presently a professor of library and information studies, Department of Education, College of Education, Psychology and Human Studies, Aoyama Gakuin University, JAPAN. From April 2014, he holds the position of the President of the Japan Society of Library and Information Science (JSLIS). And he serves five years as a member of Standing Committee, Education and Training Section (SET), International Federation of Library Associations and Institutions (IFLA). He has authored of many books and articles on the 
information services, the information management, the development of education and training methods for librarianship, and so on.

Teruyo HORIKAWA is a professor of library and information studies, Humanity and Society Major, Department of Liberal Arts, Aoyama Gakuin Women's Junior College, Japan. She is presently in the chair of the committee in Ministry of Education, Culture, Sports, Science and Technology (Japan) about school librarian staff's roles and competencies. She has authored of many books and articles on teaching and learning that utilized a school library, children's service at public library, and so on.

Yutaka MABE is assistant professor of Department of Management, Faculty of Modern Life, Teikyo Heisei University, Japan. After having an experiment of profession librarian at a prefectural library for thirteen years, he got a position of associate professor at Hokuriku Gakuin Junior College. His main concerns are about reference books, electronic books and digital library. 